\title{
Menstrual characteristics and prevalence of menstrual disorders among secondary school girls in rural Gambia
}

\begin{abstract}
Background: Menstruation is a normal physiological process in women of reproductive age and abnormalities can be associated with it. This study is conducted to determine menstrual characteristics and the prevalence of menstrual disorders among secondary school girls of rural Gambia and its effects on the life-style of these girls particularly absenteeism at school.
\end{abstract}

Method: A prospective cross-sectional survey was carried out among girls of age 13- 24 years from three different school in Soma Town, Lower River Region of The Gambia using self-administered questionnaire. The data was entered into computer database and analysed using the SPSSS version 26.

Results: The mean age of menarche was $13.86 \pm 1.26$ years with a wide range (8- 17years). Most (69.4\%) participants declared their periods as regular and mean menstrual cycle was $26.28 \pm 3.25$ days with most (58.3\%) had moderate menstrual flow with mean duration of flow was $4.9 \pm 1.3$ days. Most (69.4\%) participants used sanitary pads. Dysmenorrhea was reported by $85.2 \%$ of the participants; majority $(47.5 \%)$ had moderate pain and only $46.8 \%$ used analgesics for dysmenorrhea. Majority $(94.6 \%)$ of the participants had associated symptoms with menstruation; tiredness, mood changes and pain were the three highest reported symptoms. School absenteeism was reported by $34.5 \%$ of the participants and painful menstruation was the highest reported cause. Most (58.0\%) reported life-style affected by menstruation; attending school, casual work at home and relationship with friends were the three highest affected activities reported due painful menstruation. Almost (99.5\%) all have received some information about menstruation either from parents, teachers, friends and others.

Conclusion: Mean age at menarche was 13.86 \pm 1.26 . Most girls suffer from dysmenorrhea which affects their school attendance and other life-style activities. Almost all have received some information about menstruation.

Keywords: menstrual characteristics, dysmenorrhea, menstruation, prevalence
Volume 7 Issue 6 - 202I

\author{
Anyanwu M,',2 Mahmood S' \\ 'Edward Francis Small Teaching Hospital (EFSTH), The Gambia, \\ Gambia \\ ${ }^{2}$ School of Medical and Allied Health Sciences, University of The \\ Gambia, Gambia
}

Correspondence: Matthew Anyanwu, Consultant Obstetics \& Gynaecology at Edward Francis Small Teaching Hospital. Senior Lecturer at School of Medicine University of The Gambia. P.O Box 1416,Tel +2207786700, Email anyanwum@yahoo.com, manyanwu@utg.edu.gm Received: November 17, 202 | | Published: December 21,
202|
Abbreviations: EFSTH, edward francis small teaching hospital; WHO, World health organization

\section{Introduction}

Menstruation is the periodic changes that occur in female humans and higher apes consisting chiefly in a flow of blood from the uterine cavity and associated with various constitutional disturbances. ${ }^{1,2}$ Menstrual products consist of shedding of epithelial lining of uterus and flow of blood, cervical mucous and vaginal secretions through the vagina and last from 3 to 7 days; longer than this is considered abnormal. ${ }^{3,4}$ Menstruation starts in girls around the age of 10-16 years, with a peak age of 13 years and this is called menarche. ${ }^{5}$ The age of menarche is variable depending on the genetics, sociocultural, nutritional factors, general health, exposure to light, psychological state, racial and geographical factors. ${ }^{6,7}$ However, the average age of menarche in the United States is 12.5 years, ${ }^{8}$ and in the United Kingdom the average age of menarche is about 12.5 years. ${ }^{6}$ Menarche in Ghana is 12.5 years with modal age of 13 years; $23.5 \%$ of girls experienced their menarche before 12 years and four out of every five girls had their menarche before 14 years. ${ }^{9}$ Menstrual disorders are abnormalities that are associated with menstrual cycle and it is one of the most common reason for women to attend to the general practitioner ${ }^{10}$ and they may not be life threatening but they can cause serious social, psychological and even occupational effects. ${ }^{10}$ Some of the common symptoms associated with menstrual disorders are abdominal/pelvic pain, back pain, nausea, breast tenderness, excessive bleeding, irregular bleeding, fatigue and abnormal length of the cycle. Pain during menstruation is experienced by $70-91 \%$ of teenage girls ${ }^{11}$ and in $14-51 \%$ caused absence from school and interference with daily life activities in $15-59 \%$ of teenage girls. ${ }^{11}$

A study conducted on Australian teenage girls to determine the menstrual pattern and menstrual abnormalities with objective of establishing the typical experience of menstruation for senior secondary school girls to determine how many experienced considerable menstrual disturbances that could require further investigations. It was a cross-sectional study on 1051 girls between the ages of 15 and 19 years. The study concluded that the pain during menstruation was higher than initially reported and the pattern of analgesics use showed remarkable different from past studies. School absenteeism was consistent with the $14-51 \%$ reported in the literature. ${ }^{11}$

In another study conducted in Accra, Ghana to analyse the menstrual characteristics in 456 participants between the ages of 14-19 years from senior secondary schools. It was concluded that age of menarche and menstrual characteristics were similar to what was reported by other scholars working elsewhere. However, some 
adolescent girls in the city of Accra could be attaining their menarche at an earlier age than expected and their source of information about menstruation was mostly from their parents. ${ }^{9}$

In another cross-sectional descriptive survey using selfadministered questionnaire conducted at the Obafemi Owolowo University Ile-Ife, Nigeria in April 2007. The study concluded that the age of menarche was one year earlier than the findings from a similar study conducted about 2 decades ago in the same institution.

In Egypt, researchers working on adolescent menstrual patterns and disorder concluded with findings consistent with other studies conducted elsewhere however, the prevalence of menstrual disorders was higher. ${ }^{12}$ Dysmenorrhea in this study was $93 \%$ which was higher than the $80 \%$ reported by El-Gilany et al. and similar to the upper value in the range 59-93\% commonly reported for the same age group. Severe pain in this study ( $22 \%$ of girls) was consistent with the $14-25 \%$ reported in previous studies. Another cross-sectional study was conducted in Istanbul, Turkey among nursing students between December, 2009 to February, 2010 to determine the prevalence of dysmenorrhea in university students in Turkey: effects on daily activities and evaluation of different pain management methods. It was concluded from this study that dysmenorrhea is highly prevalent among university students and was related to school absenteeism, ability to participate in and enjoy daily activities, and limitations in social activities/functioning. ${ }^{12,13}$

A descriptive cross-sectional study was conducted in Osogbo, South Western Nigeria to determine the patterns of menstruation as well as the prevalence of menstrual disorders and their consequences among adolescent girls. Adolescent school girls aged 10-19 years comprised the sample and a total of 391 respondents. It was concluded from the study that the prevalence of menstrual disorders among adolescents in the Osogbo, South West Nigeria is high and measures should be undertaken to educate the adolescents and their mothers about menstrual disorders and to mitigate their effects on the social and academic lives of these adolescents. ${ }^{14}$

\section{Methodology}

Study population: The study was conducted among girls who were menstruating between the age of 10- 24 years and studying at secondary school in Soma Town, about $180 \mathrm{~km}$ from Banjul on the South Bank Road located almost in the centre of the country. Not many researches have been conducted in this area due to harsh environmental conditions and low educational level of the people and lack of any institution involved in research in the community. This part of the country also lacks proper medical facilities and the population socio-economic status is generally poor.

Study design: A prospective cross-sectional survey was carried out in three secondary schools in Soma Town. In Jarra West District, Lower River Region (LRR) on the South Bank.

Data collection tool: A questionnaire was used to collect the data. The participants did not provide their personal information in order to avoid individual identification. Parameters studied includes current age, age of menarche, regularity of the periods, menstrual cycle length, quantity of menstrual bleeding, duration of menstrual bleeding, abdominal pain with menstruation, severity of pain, effect of menstruation on life-style, school absenteeism and sanitary materials used during menstruation.

Procedure: Each participant was explained the purpose of the study and their willingness to participate was respected. After obtaining an informed consent, each participant was given the questionnaires to answer which on average took about 20 minutes to answer. No identification of the participants was made but each of the questionnaire and the consent form were serialy numbered the same as questionnaire. Both were given to each person. The questionnaire was prepared in English. The Science teacher(s) within the schools helped in the data collection process.

Sample size: A study showed prevalence of menstrual disorders among adolescence girls of $87.7 \%(15)$ and using the modified Leslie Kish Formula (16), sample size of 173 was obtained. The formula is $\mathrm{N}=4 \mathrm{pq} / \mathrm{e} 2$ where $\mathrm{N}$ is "sample number required", $\mathrm{p}$ is the "prevalence", q is " 1 -prevalence" and e is "error for precision for the estimate (which is 0.05 )". Substituting the values into the formula: $N=$ $(4 \times 0.877 \times 0.123) / 0.052$ which gives the value for sample size to be 172.59 and it can be rounded up to 173. Assuming the non-response rate of $10 \%$, which will be 17.3 and approximately it was 17 ; a sample of 190 was obtained. However, 425 questionnaires were distributed but 386 were used for the purpose of analysis.

\section{Inclusion and exclusion criteria}

Menstruating girls between the ages of 10-24 years who were willing to participate in the study were included in the study. Girls that were not menstruating or pregnant or breastfeeding were excluded from the study.

Statistical analysis: Data was entered into a computer database and analysed with Statistical Package for Social Sciences (SPSS) for Windows version 26 . The results were presented in tables and charts. Test of significance using chi square was performed and $\mathrm{p}$-Value of $<0.05$ was considered statistically significant.

\section{Ethical consideration}

No personal information from the participants were collected in order to avoid individual identification. Informed consent was obtained from all the participants and parental approval was also obtained from all the participants that were less than the age of 18 years. The information confidentiality, privacy and study approval from reputable scientific and ethics committee of School of Medicine and Allied Health Sciences, University of the Gambia was obtained. The principals of the schools were contacted to seek their consent for the research to be conducted in their schools and an approval was given.

\section{Results}

A total of 425 questionnaires with the consent form were distributed and 400 questionnaires with their signed consent forms were received back. 1 questionnaire was not filled and 7 cases did not have current age specified on them and 6 girls responded "not menstruating". Hence, a total of 386 questionnaires fulfilled the inclusion and exclusion criteria and were analysed for the purpose of this study.

Figure 1: Age Demographic; The least age of participation was 13 years and the highest age was 24 years. The mean age of participants was 16.74 years, the standard deviation is 1.60 years, median age was 17 years and mode age was 16 years. Most $(79.8 \%)$ of the participants were between the age of 15 to 18 years, $56(14.5 \%)$ of the participants were above 19 years and $22(5.7 \%)$ of the participants were less than 15 years.

Table 1: Menstrual Characteristics: Minimum age of menarche reported was 8 years and maximum age was 17 years. Most (96.6\%) of the participants reported the age of menarche between 12 to 16 years with a range from 8 to 17 years and mean age of 13.86 years; 
the median and modal age was 14 years and standard deviation 1.26 . Most, 268 (69.4\%) of the participants defined their periods as regular while $102(26.4 \%)$ of the participants defined their period as irregular and $16(4.1 \%)$ of the participants did not know if their periods are regular or irregular and this was due to them not paying attention to it.
The mean duration was $26.28 \pm 3.25$ days, mode was 28 , median was 27. Majority $(93.73 \%)$ of the participants' cycle length raged from 21 to 35 days, $15(5.6 \%)$ of the participants' cycle length was less than 21 days and $1(0.4 \%)$ of the participants had their cycle for more than 35 days.

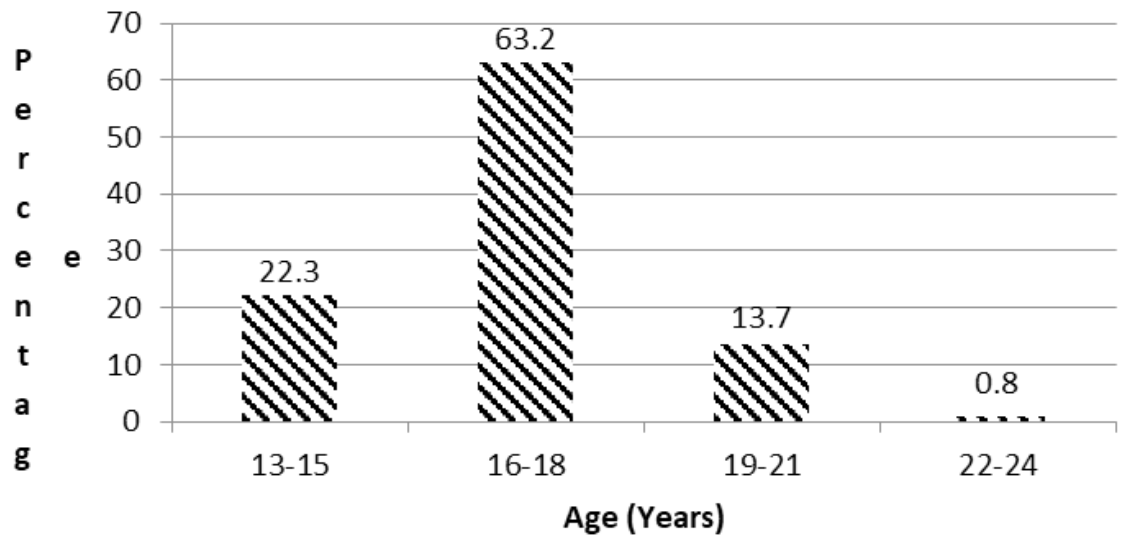

Figure I Age demographic.

Table I Menstrual characteristics

\begin{tabular}{|c|c|c|c|}
\hline Menstrual characteristics & Parameters & Frequency & Percentage \\
\hline \multirow[t]{6}{*}{ Age of Menarche } & $8-9$ & 3 & 0.8 \\
\hline & $10-11$ & 7 & 1.8 \\
\hline & $12-13$ & 119 & 30.8 \\
\hline & $14-15$ & 235 & 60.9 \\
\hline & $16-17$ & 22 & 5.7 \\
\hline & Total & 386 & 100 \\
\hline \multirow[t]{4}{*}{ Regularity of Periods } & Regular & 268 & 69.4 \\
\hline & Irregular & 102 & 26.4 \\
\hline & Don't know & 16 & 4.1 \\
\hline & Total & 386 & 100 \\
\hline \multirow[t]{5}{*}{ Length of Cycle } & $\leq 20$ Days & 15 & 5.9 \\
\hline & 2I-27 Days & 137 & 53.7 \\
\hline & 28-35 Days & 102 & 40 \\
\hline & $\geq 36$ Days & I & 0.4 \\
\hline & Total & 255 & 100 \\
\hline \multirow[t]{4}{*}{ Amount of Bleeding } & Mild & 64 & 17.1 \\
\hline & Moderate & 218 & 58.3 \\
\hline & Severe & 92 & 24.6 \\
\hline & Total & 374 & 100 \\
\hline \multirow[t]{6}{*}{ Duration of Menstrual Flow } & 2-3 Days & 40 & 10.4 \\
\hline & 4-5 Days & 261 & 67.6 \\
\hline & 6-7 Days & 77 & 19.9 \\
\hline & 8-9 Days & 6 & 1.6 \\
\hline & $\geq 10$ Days & 2 & 0.5 \\
\hline & Total & 386 & 100 \\
\hline
\end{tabular}


Table Continued...

\begin{tabular}{|c|c|c|c|}
\hline Menstrual characteristics & Parameters & Frequency & Percentage \\
\hline \multirow[t]{6}{*}{ Sanitary Material Used } & Pads & 268 & 69.4 \\
\hline & Clothes/Towels & 63 & 16.3 \\
\hline & Pads + Clothes/Towels & 48 & 12.4 \\
\hline & Pads + Clothes/Towels + Others & 3 & 0.8 \\
\hline & Others & 4 & 1 \\
\hline & Total & 386 & 100 \\
\hline \multirow[t]{7}{*}{ Number of Sanitary Materials used per day } & 1 & 15 & 3.9 \\
\hline & 2 & 69 & 17.9 \\
\hline & 3 & 165 & 42.7 \\
\hline & 4 & 95 & 24.6 \\
\hline & 5 & 32 & 8.3 \\
\hline & $\geq 6$ & 10 & 2.6 \\
\hline & Total & 386 & 100 \\
\hline \multirow[t]{3}{*}{ Abdominal Pain during Menses } & Yes & 329 & 85.2 \\
\hline & No & 57 & 14.8 \\
\hline & Total & 386 & 100 \\
\hline \multirow[t]{3}{*}{ Medication Used } & Yes & 153 & 46.8 \\
\hline & No & 174 & 53.2 \\
\hline & Total & 327 & 100 \\
\hline \multirow[t]{7}{*}{ Type of Medication Used } & Paracetamol & 23 & 16.2 \\
\hline & Paracetamol + Diclofenac & 75 & 52.8 \\
\hline & Ibuprofen & 10 & 7 \\
\hline & Buscupam & 1 & 0.7 \\
\hline & Traditional Herbs/Methods & 23 & 16.2 \\
\hline & Others & 10 & 7 \\
\hline & Total & 142 & 100 \\
\hline \multirow[t]{3}{*}{ Associated symptoms with menses } & Yes & 365 & 94.6 \\
\hline & No & 21 & 5.4 \\
\hline & Total & 386 & 100 \\
\hline \multirow[t]{11}{*}{ Symptoms associated with Menses } & Tiredness & 127 & 34.8 \\
\hline & Mood change & 126 & 34.5 \\
\hline & Pain down the legs & 86 & 23.6 \\
\hline & Appetite change & 81 & 22.2 \\
\hline & Frequent urination & 66 & 18.1 \\
\hline & Headache & 62 & 17 \\
\hline & Change in sleeping pattern & 55 & 15.1 \\
\hline & Diarrhoea & 55 & 15.1 \\
\hline & Dizziness & 51 & 14 \\
\hline & Depressed & 43 & 11.8 \\
\hline & Nausea & 37 & 10.1 \\
\hline
\end{tabular}




\begin{tabular}{|c|c|c|c|}
\hline Menstrual characteristics & Parameters & Frequency & Percentage \\
\hline & Bloating & 33 & 9 \\
\hline & Vomiting & 32 & 8.8 \\
\hline & Indigestion & 29 & 7.9 \\
\hline & Constipation & 25 & 6.8 \\
\hline & Others & 7 & 1.9 \\
\hline & Total $(\mathrm{N})$ & 365 & \\
\hline
\end{tabular}

See Table 1. Sixty-four (17.1\%) of the girls defined their bleeding as mild, $218(58.3 \%)$ described it as moderate and $92(24.6 \%)$ of the girls defined their bleeding as heavy bleeding. Duration of menstrual flow ranged from 2-15 days. The mean duration of bleeding was $4.9 \pm 1.3$; mode and median 5 days. Majority $(97.4 \%)$ of the participants declared 3-7 days of menstrual flow while two $(0.5 \%)$ girls had less than three days of bleeding and $48(10.4 \%)$ had more than 7 days of bleeding.

All the participants used some kind of sanitary material during their menses. Majority $(69.4 \%)$ of the participants used pads only as their sanitary material, $63(16.4 \%)$ used clothes/towels, 4 (1\%) used other items or none at all, $48(12.5 \%)$ used both pads and clothes/ towels depending on the availability, and $3(0.8 \%)$ used pads, towels/ clothes, or none subjected to the circumstances. The mean number of sanitary materials used was $3.26 \pm 1.15$ per day. Majority $(93.5 \%)$ of the participants used 2 to 5 sanitary materials per day, $15(3.9 \%)$ of the participants used less than two sanitary materials per day, while 10 $(2.6 \%)$ of the participants used more than 6 sanitary materials per day.

Around $(85.2 \%)$ of the girls reported having abdominal pain during menses. About (17.8\%) of the girls defined their pain as mild, $155(47.5 \%)$ of the girls defined pain as moderate and $113(34.7 \%)$ girls defined their pain as severe. One hundred and Seventyfour $(53.2 \%)$ of girls do not use any medicine despite the pain they suffer and $153(46.8 \%)$ of girls used medicine for the pain during their menses. Combination of Paracetamol and Diclofenac was the highest used modality by $75(52.8 \%)$ of the participants and $23(16.2 \%)$ of the participants use exclusively the traditionally available herbs and methods for the management of their pain.

Majority (94.6\%) of the girls reported some symptoms associated with menses, $21(5.4 \%)$ of the girls reported no symptoms associated with menses. Tiredness was the highest $(34.8 \%)$ reported symptom followed by mood change (34.5\%), pain down the legs $(23.6 \%)$ and Appetite Change (22.2\%) Table 1.

Table 2: Life Style Affected; Fifty Eight Percent (58.0\%) of the girls' lifestyle is affected by menstruation. Attending school was the highest (33.5\%) activity affected, followed by "casual work at home" $(32.6 \%)$. Relationship with friends, social activities, relationship with friends, relationship with family and doing school work is also significantly affected. Painful menses is reported as the highest cause of lifestyle activity affected by $59.4 \%$ of the participants of the study. Mood change, feeling sick and heavy bleeding are also significantly reported.

Table 2 Life-style affected by menstruation

\begin{tabular}{llll}
\hline Variable & Parameters & Frequency & Percentage \\
\hline Lifestyle affected by menses & Yes & 224 & $\mathbf{5 8}$ \\
& No & 162 & 42 \\
Total & 386 & 100 \\
& Attending school & 74 & 33.5 \\
& Casual work at home & 73 & 33 \\
& Relationship with friends & 63 & 28.5 \\
& Social activities & 59 & 26.7 \\
& Sports and exercise & 56 & 25.3 \\
& Doing school work & 38 & 17.2 \\
& Relationship with family & 35 & 15.8 \\
& Relationship with partner & 26 & 11.8 \\
& Sexual activity & 10 & 4.5 \\
Others & 3 & 1.4 \\
\hline Total (N) & 121 & \\
\hline
\end{tabular}




\begin{tabular}{llll} 
Table Continued... & Parameters & Frequency & Percentage \\
\hline Variable & Painful Menses & 130 & 59.4 \\
Cause of activity affected & Mood Changes & 47 & 21.5 \\
& Heavy Bleeding & 40 & 18.3 \\
& Felling sick & 49 & 22.4 \\
& Tiredness/Fatigue & 32 & 14.6 \\
& Others & 7 & 3.2 \\
& Total (N) & 219 &
\end{tabular}

Source of Information: $284(99.5 \%)$ have received some kind of information menstruation either in class, workshops, group talks among friends and family or through any other source. Most of the girls obtained information from parents $(44.1 \%)$, from teachers $(29.5 \%)$, from friends $(25.8 \%)$ of the cases and from other sources $0.7 \%$ of the girls which included sisters, religious leaders internet and books. Most girls had more than one source of information (Figure 2).

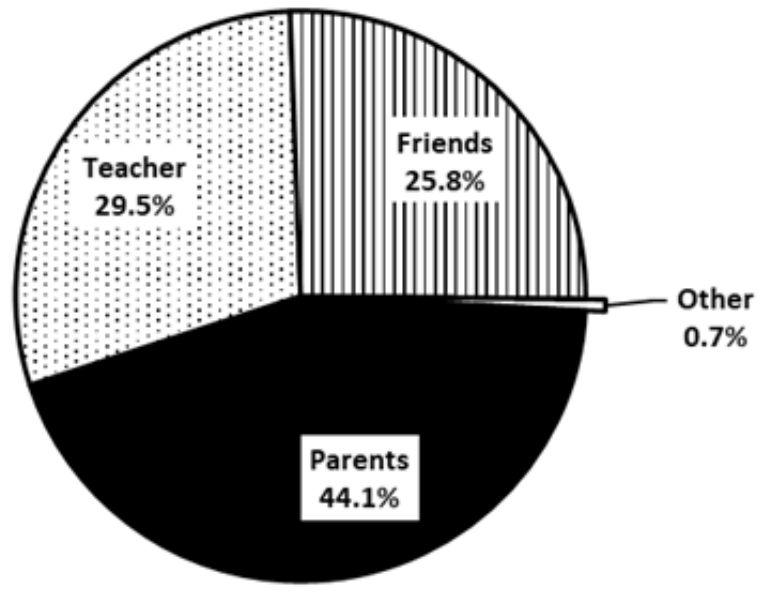

Figure 2 Sources of information regarding menstruation.

\section{Discussion}

This study was done to determine the menstrual characteristics and prevalence of menstrual disorders among young girls in the Lower River Region of the Gambia who are in secondary schools. Three hundred and eighty-six girls between the ages of 13 to 24 years in secondary school were recruited as study population. The mean age of participant was $16.74 \pm 1.60$ years which is higher than in a study conducted in Egypt ${ }^{12}$ but similar to a study done in Accra, Ghana ${ }^{11}$ and lower than a study done in Italy. ${ }^{23}$ The mean age of menarche in this study was $13.86 \pm 1.26$ years; the range was 8 to 17 years of age and the median and mode was 14 years. It was higher than the age of menarche reported in other studies. ${ }^{9}, 11,12,14,17,18$ Majority $(69.4 \%)$ of the girls reported regular periods and $26.4 \%$ of the girls reported irregular periods, this was similar to the results reported in other studies. ${ }^{911,12,17}$ The mean length of the menstrual cycle reported in this study was $26.28 \pm 3.25$ days and mode is 28 days which was similar to the once reported in other studies (9). Most (93.73\%) of the girls had their periods between 21-35 days which was consistent with the study conducted in Egypt ${ }^{11}$ but higher than reported in some other studies. ${ }^{14,16}$

Majority $(58.3 \%)$ of the participants reported moderate amount of bleeding and $24.6 \%$ of the participants reported heavy bleeding.
The average duration of bleeding reported was $4.9 \pm 1.3$ days; this was consistent with findings in other studies. ${ }^{9,12}$ Majority (69.4\%) of the girls used pads during their menses and this was mostly due the provision of pads at the schools by Non-Governmental Organisations, $16.3 \%$ of the participants reported using clothes only as their sanitary material during menstruation and this was mostly due to limited availability of the pads to them and this may increases their risk for infections due to poor hygiene. An India study showed higher percentage (44\%) of pad users. The average number of sanitary materials used per day was $3.26 \pm 1.15$ similar to what the study conducted in India reported. ${ }^{19}$ Most $(85.2 \%)$ of the girls reported abdominal pain during menses which was less than reported in other studies ${ }^{11-13,17}$ but higher than reported elsewhere. ${ }^{9,14}$ The participants reported their pain as severe $(34.7 \%)$, moderate $(47.5 \%)$ and mild $(17.8 \%)$ which was similar to other studies conducted elsewhere. ${ }^{13,17}$

About half (46.8\%) of the participants that have pain used some kind of analgesics or traditional method to manage their pain during menstruation and a combination of paracetamol and diclofenac (NSAIDs) was the most common $(52.8 \%)$ medication used. This combination was readily available in the various commercial pharmacies located within the community and they are sold over the counter at a cheaper rate making the accessibility easy and saving the young girls from the stigma attached with them going to the local health centre waiting in queue for longer duration. Some $(16.2 \%)$ girls have also reported using traditional herbs during their menstrual pain which included the use of boiled Guava leaves (drink and wash the genitals), sitting in a tub filled warm salty water and use of other herbs locally available were highly reported traditional methods. The participants that did not use any form of analgesics for their pain commonly had the belief that it is a natural cause and every woman goes through it. Similar agents to manage dysmenorrhea have been reported in other studies. ${ }^{12,17,19-21}$

Majority (94.6\%) of the participants reported some symptoms associated with their menstruation and tiredness, mood change, pain down the legs, appetite change and frequent urination were the five most common reported symptoms and these finding were very close to the findings reported in another study. ${ }^{11}$ The symptoms reported by the participants were within the scope of the symptoms reported by other scholars working elsewhere. ${ }^{12}$ Majority $(58.0 \%)$ of the girls had their life style affected by menstrual periods and school absenteeism, doing casual work at home, relationship with friends, social activities and sports and exercise were the five most common reported activities affected by menstruation and dysmenorrhoea. Lifestyle affectation by menstruation in the adolescence has been well established in the literature. ${ }^{12,13}$ School absenteeism due to menstruation was reported by $33.5 \%$ of the girls and dysmenorrhea was the highest reported cause. Similar findings have been reported in other studies. ${ }^{11-13}$ Almost all the participants had counselling and some information 
about menstruation. Most of the participants had more than one source of information. Majority (44.1\%) received information from their parents, $29.5 \%$ from their teachers during class or during workshops and seminars, $25.8 \%$ discussed it among friends and $0.7 \%$ discussed it with their respective religious scholars, sisters and other relatives. Similar sources of information have been reported in Ghana ${ }^{9}$ but lower percentage is reported in a study in Egypt ${ }^{12}$ with no school education on menstrual cycles reported by the participants.

Limitations: This study was conducted in only one region of the country and may not apply to the entire population of the country. The results and analysis were based on the information obtained from the participants and some participants may not have provided all information required due to their personal believes and the education level or the understanding of the issues surrounding the menstrual cycle.

\section{Conclusion}

The average age of menarche was $13.86 \pm 1.26$ years. Most (69.4\%) of the girls reported regular periods with mean length of menstrual cycle of $26.28 \pm 3.25$ days and most $(58.3 \%)$ of the participants had moderate amount of menstrual flow with average duration of bleeding $4.9 \pm 1.3$ days. Majority $(69.4 \%)$ of the participants used pads as their sanitary material. Many $(94.6 \%)$ reported symptoms associated with menstruation and dysmenorrhea was highly reported in this study. About $47 \%$ of the participants with pain used either a pharmacological drug or the traditional method/herbs to manage their pain. Most (58.0\%) of the girls had their life-style affected by menstruation and painful menstrual periods was the highest reported cause of the life-style affectation. Dysmenorrhea affected the school attendance of the girls. This study also showed that all participants had some information about menstruation either from their parents, teachers, sisters, friends or other sources.

\section{Recommendations}

More information should be offered to girls about menstruation in a more friendly settings to encourage the girls to speak about it. They should be informed about the symptoms that could be associated with menstruation particularly the pain and how it can be managed with safer, available and affordable medications as demonstrated in this study. The NGOs and other organisations should be encouraged to continue providing sanitary pads and parents/guardians should emulate the good gestures so that it becomes sustainable. The use of clothes and other material that may not be very clean should be discouraged. Reproductive health clinics should be made accessible and more adolescent friendly to address the dysmenorrhea and other symptoms associated with menstrual cycle to decrease morbidity and dispel myths.

\section{Acknowledgments}

The authors wish to thank the principals and science teachers of the 3 schools used in this study for their immense support during data collection. To the parents who gave consents for their children and in one way or the other enhance smooth data collection we say a big thank you. Competing interests: The authors declare that they have no competing interests

\section{Authors' contributions}

MS conceived the study and contributed to the study design, data collection, and data analysis. MA wrote the manuscript. All authors read and approved the final manuscript.

\section{Availability of data and materials}

The datasets generated and/or analysed during this study are available from the corresponding author on reasonable request.

\section{Consent to publish}

Not applicable.

\section{Ethics approval and consent to participate}

Ethical clearance to undertake this study was sought from the Research and Publication Committee at the School of Medicine and Allied Health Sciences, University of The Gambia and approval was granted. Participants identifiable information were careful kept and was neither used nor shared. Consent to participate in the study was bilaterally secured (from the principal of the school, parents of those below 18 years and participants themselves).

\section{Funding}

The authors did not receive any funding from any source to carry out this study.

\section{References}

1. Marcovitch Harvey. Black's Medical Dictionary. 41st ed. London, A \& C Black Publishers Limited, 2005

2. Dutta DC, Konar Hiralal. DC Dutta's Textbook of Gynaecology, 6th ed New Delhi, Jaypee Brothers Medical Publishers LTD. 2013. 82 p.

3. Steve N London, Abnormal Uterine Bleeding, In: James R Scott, editor Danforth's Obtetrics and Gynaecology, 9th ed. United States, Lippincott Williams \& Wilkins Publisher. 2019;343-349 .

4. Alexandra P Young, Deborah B Proctor. Kinn's The Medical Assistance An Applied Learning Approach, 10th ed. United States of America, Saunders Elsevier. 2007. 847 p.

5. Dutta DC, Konar Hiralal. DC Dutta's Textbook of Gynaecology, 6th Ed. New Delhi, Jaypee Brothers Medical Publishers LTD. 2013. 50 p.

6. Marcovitch Harvey. Black's Medical Dictionary, 41st ed. London, A \& C Black Publishers Limited, 2005.

7. Rebar Robert W, Puberty, In:Berek Jonathan S, editor. Novak's Gynaecology, 13th ed. Lippincott Williams and Wilkins, 2019.

8. Anderson SE, Dallal GE, Must A. Relative weight and race influence average age at menarche:results from two nationally representative surveys of US girls studied 25 years apart". Pediatrics. 2003;111(4):844850.

9. Gumanga SK, R A Kwame-Aryee. Menstrual characteristics in some adolescent girls in Accra, Ghana. Ghana Med J. 2012;46(1):3-7.

10. Monga Ash, Dobbs Stephen. Gynaecology by Ten Teachers, 19th ed. CRC Press. 2011

11. Parkar MA, Sneddon AE, Arbon P. The menstrual disorder of teenagers (MODT) study:determining typical menstrual patterns and menstrual disturbance in a large population based study of Australian teenagers. General Gynaecology. 2009;185-191.

12. Hatem I Abdelmoty, M A Youssef, Shimaa Abdallah, et al, menstrual patterns and disorders among secondary school adolescents in Egypt. A cross-sectional survey. BMC Women's Health. 2015.

13. Dilek Coskuner Potur, Nevin Citak Bilgin, Nuran Komurcu, et al. Prevalence of dysmenorrhea in university students in Turkey:Effect on daily activities and evaluation of different pain management methods, Nursing pain management. 2014;5(4):768-777. 
14. Amu Eyitope O, Bamidele James O, Prevalence of menstrual disorders among adolescent girls in Osogbo, South Western Nigeria, International journal of adolescent medicine and health. 2014;26(1).

15. Ravi Ram, et al, Prevalence of menstrual problems among adolescent girls in rural Tamil Nadu. Journal of paediatrics and adolescent gynaecology. 2016;29(6):571-576.

16. Community Medicine for All Seeking Simple Explanations, Sample size calculation:Cross sectional studies. 2019.

17. Ihsan Esen, Baran Ogus, Hepsen Mine Serin. Menstrual characteristics of pubertal girls:a questionnaire-based study in Turkey, Journal of clinical research in paediatric endocrinology. 2015.

18. Monika Singh, Om Prakash Rajoura, Raghavendra A Honnakamble, et al. Pattern and problems of menstruation among the adolescent girls of Delhi:a cross-sectional study, International Journal of community medicine and public health. 2019.
19. Karthik Balajee Laksham. Menstrual disorders and quality of life of women in urban area of Puducherry:A community-based cross-sectional study, Journal of family medicine and primary care, Published by Wolters Kluwer-Medknow. 2019;137-140.

20. Michelle Proctor, Cynthia Farquhar. Diagnosis and management of dysmenorrhea. BMJ. 2006;332:1134-1138 21.

21. Franco Rigon, Vincenzo De Sanctis, Sergio Bernasconi, et al. menstrural pattern and menstural disorders among adolescents:an update of the Italian data, Italian journal of paediatrics. BioMed Central ltd. 2012. 